\title{
Fatty acid composition and antioxidant capacity of some medicinal mushrooms in Turkey
}

\author{
Ibrahim Türkekul $^{1}$ (D) Fatma Çetin ${ }^{2} \cdot$ Mahfuz Elmastaş $^{2}$ (D)
}

Received: 4 October 2016 / Accepted: 3 November 2016 / Published Online: 31 March 2017

(C) The Korean Society for Applied Biological Chemistry 2017

\begin{abstract}
Turkey has a very rich fungal flora due to its phytogeographical position. The screening of chemical content and active substances of mushrooms becomes an important subject not only for Turkey but also for all over the world. In the last decade, Analyses on phytochemical and biological activity of fungi have gradually increased as a result of improvement in the number and quality of facilities. In the scope of the present research, four medicinal mushrooms; Morchella elata, Lactarius volemus, Cantharellus cibarius and Tricholoma terreum were analyzed for their fatty acid compositions and antioxidant capacities. The fungal species have been found with unsaturated fatty acid/saturated fatty acid ratio of 6.73 for Morchella elata, 4.12 for Lactarius volemus, 5.21 for Cantharellus cibarius, 3.73 for Tricholama terrum. In addition, the concentration of malondialdehyde which was an indicator of lipid peroxidation was also determined in these species. According to the results, free radical scavenging activity of Morchella elata and Lactarius volemus were found higher than the other species. Any of the mushroom species investigated were found having very high metal chelating activity. The results showed that the extract of Morchella elata and Lactarius volemus exhibited significant antioxidant activities. Hence, the mushrooms have a potential to be a natural antioxidant in food industries as antioxidant agent.
\end{abstract}

Ibrahim Türkekul $(\bowtie)$

E-mail: ibrahim.tukekul@gop.edu.tr

Mahfuz Elmastaş $(\bowtie)$

E-mail:mahfuz.elmastas@gop.edu.tr

${ }^{1}$ Department of Biology, Faculty of Arts and Science, Gaziosmanpaşa University, 60240-Tokat, Turkey

${ }^{2}$ Department of Chemistry, Faculty of Arts and Science, Gaziosmanpaşa University, 60240-Tokat, Turkey

This is an Open Access article distributed under the terms of the Creative Commons Attribution Non-Commercial License (http://creativecommons. org/licenses/by-nc/3.0/) which permits unrestricted non-commercial use, distribution, and reproduction in any medium, provided the original work is properly cited.
Keywords Antioxidant Capacity $\cdot$ Fatty Acid $\cdot$ Malondialdehyde Medicinal Mushroom

\section{Introduction}

Wild edible mushrooms are preferred by many people due to their flavour and texture (Sanmee et al. 2003). Some of them have important medicinal properties as well. They can be used in preventive medicine against various diseases such as hypertension, hypercholesterolemia, antidiabetic and cancer (Manzi et al. 2001). Some of them can be evaluated as candidates for development of novel medicines and nutraceuticals due to their chemical compositions (Elbatrawy et al. 2015). Fruit body of mushrooms accumulates a variety of bioactive metabolites with immunomodulatory, cardiovascular, liver protective, anti-fibrotic, anti-inflammatory, antidiabetic, antiviral, antioxidant, antitumor and antimicrobial properties (Vaz et al. 2012; Qin et al. 2015).

Medicinal mushrooms with biologically active substances are currently under human clinical trials and some promising results were obtained on their usage in conventional therapies (Money 2016). Morels (Morhella spp.) are reported to be used as a source of immunostimulants, antitumor agents and medicinal adaptogens (Nitha et al. 2007). Some compounds extracted from Tricholoma terreum were found to have cytotoxic effects against five human cancer cell lines (Yin et al. 2013). Cantharellus cibarius is a beneficial nutrient for human health with high levels of vitamins B and C (Muszynska et al. 2013). Lactarius volemus is a source of critical nutraceuticals, such as essential fatty acids and phenolic bioactive compounds (Reis et al. 2011).

Natural antioxidants can be used as an effective tool against oxidative damage which can result in ageing and degenerative diseases (Muka et al. 2015). Some mushrooms are an important source of natural antioxidants and essential fatty acids. Many studies have been conducted individually on fatty acids, antioxidant activities, mineral and trace elements of mushrooms (Ebrahimzadeh 
et al. 2010; Falandysz, Drewnowska 2015; Goyal et al. 2015). But malondialdehyde (MDA), antioxidant properties and fatty acid composition of mushrooms have not been evaluated altogether. Our objective was to evaluate the antioxidant capacity, fatty acid composition and MDA contents of four wild edible medicinal mushroom species (Lactarius volemus, Morchella elata, Tricholoma terreum, and Cantharellus cibarius) collected from Turkey.

\section{Materials and Methods}

\section{Chemicals}

2,2-diphenyl-1-picryl-hydrazyl (DPPH·), ferrous chloride, $\alpha$ tocopherol and trichloracetic acid (TCA) were purchased from Sigma-Aldrich Company (Sternheim, Germany). Butylated hydroxyl toluene (BHT), thiobarbituric acid (TBA), 3-(2-Pyridyl)5,6-diphenyl-1,2,4-triazine-p,p'-disulfonic acid monosodium salt hydrate (Ferrozine) and ethylenediaminetetraacetic acid (EDTA) were purchased from Merck.

\section{Collection and extraction of the samples}

Mushrooms were collected from the Black Sea region of Turkey and identified. They have been stored at the Mycology Herbarium Laboratory of Gaziosmanpasa University (Turkey). Table 1 shows the details including herbarium number of mushroom samples used in this study.

Prior to the analyses, fresh mushrooms from each species were air-dried in an oven at $40{ }^{\circ} \mathrm{C}$ constant weight. Extraction procedure for antioxidant assays was performed according to the literature. Methanol extracts of dried mushroom samples (5g) were individually grinded into fine powders in a mill and was mixed with $50 \mathrm{~mL}$ of methanol at room temperature with vigorous mixing at $150 \mathrm{rpm}$ for $24 \mathrm{~h}$. Extracts were obtained after solvent removal under vacuum using rotary evaporator at $40{ }^{\circ} \mathrm{C}$.

\section{Extraction procedure and GC-FID condition for fatty acid content determination}

Crude oil was obtained from mushroom samples by light petroleum ether (b.p. $40-60{ }^{\circ} \mathrm{C}$ ) extraction. The solvent was removed by rotary evaporator and the extracted oil was used for fatty acid analysis.

The fatty acid methyl esters (FAMEs) of oil were obtained by transmethylation (Cantellops et al. 1999). The temperature of the injector and detector were 250 and $260{ }^{\circ} \mathrm{C}$, respectively. Fatty acid analyses were performed by Gas Chromatography equipped Flame Ionization Detector (GC-FID), Perkin Elmer Clarus 500 Series GC system, with an apolar capillary column $(30 \mathrm{~m} \times 0.25$ $\mathrm{mm}$ and $0.25 \mu \mathrm{m}$ ID). Helium was used as carrier gas. Initial column oven temperature of $100{ }^{\circ} \mathrm{C}$ was elevated to $220^{\circ} \mathrm{C}$ at a rate of $2{ }^{\circ} \mathrm{C} / \mathrm{min}$ and held there for a $10 \mathrm{~min}$. Identification of fatty acid components was accomplished based on the comparison of their retention times with the authentic standards (Supelco Company, Fatty acid Mix, Bellefonte, PA, USA). The peak area percentages of compounds were calculated based on the FID data.

\section{Determination of malondialdehyde content}

Ohya's method was used to determine the concentration of lipid peroxidation products in the mushroom (Ohya 1993). Samples ( $0.5 \mathrm{~g}$ each) were homogenized in $5 \mathrm{~mL}$ of $0.1 \%$ (w/v) TCA, and then centrifuged at $10,000 \mathrm{~g}$ for $20 \mathrm{~min} .0 .5 \mathrm{~mL}$ of the supernatant was added to $1 \mathrm{~mL}$ TBA in $20 \%$ TCA and the mixture was incubated in boiling water for $30 \mathrm{~min}$. The reaction was stopped by placing the reaction tubes in an ice bath. Then, they were centrifuged at $10,000 \mathrm{~g}$ for $5 \mathrm{~min}$, and the absorbance of supernatant was read at $532 \mathrm{~nm}$ and corrected for non-specific turbidity by subtracting the absorbance value at $600 \mathrm{~nm}$. An extinction coefficient of $1.55 \times 10^{5} \mathrm{mM}^{-1} \mathrm{~cm}^{-1}$ was used to quantify lipid peroxides and it was expressed as nmol MDA g $\mathrm{g}^{-1}$ dry weight (DW).

\section{Determination of reduction power}

The reducing power of methanolic extract of mushroom species was determined according to Oyaizu's method (Oyaizu 1988) with some modification (Canabady-Rochelle et al. 2015). Absorbance was read at $700 \mathrm{~nm}$. The higher the absorbance represents the higher the reductive capability of samples.

\section{Free radical scavenging activity}

The free radical scavenging activities of mushroom species were measured by DPPH method with some modifications (Brandwilliams et al. 1995). The absorbance was read at $517 \mathrm{~nm}$ by UV-VIS spectrophotometer.

Scavenged percentage of DPPH radical was calculated using the following equation:

$$
\text { Scavenging of DPPH }(\%)=\left(\left(\mathrm{A}_{0}-\mathrm{A}_{1} / \mathrm{A}_{0}\right) \times 100\right)
$$

where $A_{0}$ was the absorbance of the negative control as $A_{1}$ was the absorbance of the extract of mushroom species.

Table 1 Habitats, edibility and herbarium numbers of mushroom species

\begin{tabular}{|c|c|c|}
\hline Species of mushrooms & Habitat and Herbarium Number & Edibility \\
\hline Morchella eleta Fr. & In conifer woods or on chalk soil (No: 3620$)$ & Edible \\
\hline Tricholoma terreum (Schaeff.: Fr.) & In woods, especially with conifers (No: 1847) & Edible \\
\hline Cantharellus cibarius Fr. & In all kinds of woodlands (No: 2163) & Edible \\
\hline Lactarius volemus Fr. & Under bothe coniferous and broad-leaved trees (No: 2630) & Edible \\
\hline
\end{tabular}




\section{Chelating effect on ferrous Ions}

The chelating of ferrous ions by mushroom species was calculated by Dinis' method (Dinis et al. 1994) with a positive control, EDTA. The percentage of inhibition of ferrozine- $\mathrm{Fe}^{2+}$ complex formation was calculated with the following equation:

$$
\text { Percentage Inhibition }=\left(\left(\mathrm{A}_{0}-\mathrm{A}_{1}\right) / \mathrm{A}_{0}\right) \times 100
$$

where $A_{0}$ was the absorbance of the negative control as $A_{1}$ was the absorbance of extract and standards of mushroom species.

\section{Statistical analysis}

The experimental results were mean $\pm \mathrm{SD}$ of at least three independent measurements. Data were subjected to analysis of variance (ANOVA) and the group means were compared through Paired-Samples T Test or Duncan's Multiple-Range Test using SPSS 20 statistical package. $P<0.05$ were regarded as significant and $p<0.01$ as very significant.

\section{Results and Discussion}

\section{Determination of fatty acids}

In the present study, fatty acid compositions of four medicinal mushroom species: Lactarius volemus, Morchella elata, Tricholoma terreum, and Cantharellus cibarius were analyzed. Results of fatty acid composition analyses in the mushroom samples were demonstrated in Table 2. According to the Table 2, it is clearly seen that the mushroom species comprised of myristic, penthadecanoic, penthadecenoic, palmitic, oleic, linoleic, linoelaidic and eicosanoic acids. Fatty acid composition of mushroom samples shows differences between the species. Total unsaturated fatty acid (UFA) levels were ranged from 78 to $86 \%$ as the total saturated fatty acid (SFA) ranged from 12 to $21 \%$ in all four species (Table 2). Linoleic acid was observed at the highest

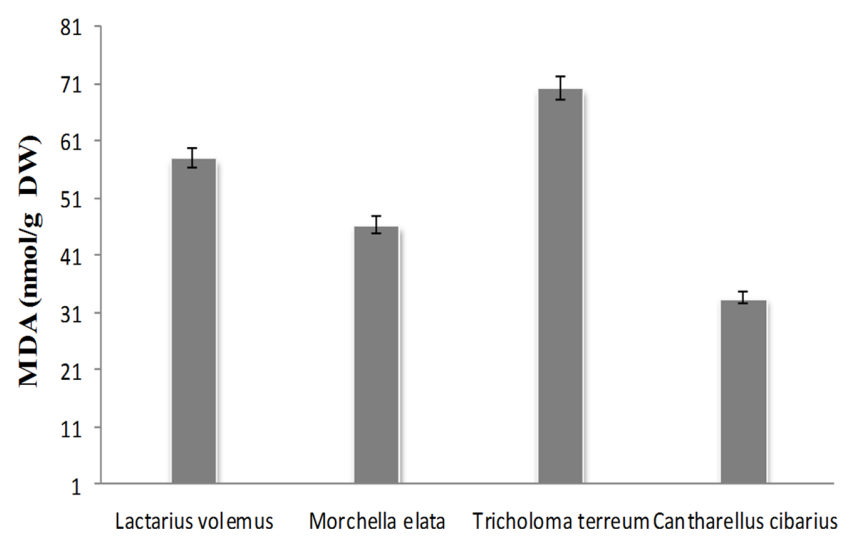

Fig. 1 MDA content of Morchella elata, Lactarius volemus, Cantharellus cibarius, Tricholoma terreum

amount except for Morchella elata which contains high amount of oleic acid (Table 2). In the earlier studies on fatty acid compositions of some mushroom species, the amount of UFA was found at the highest value. When the individual fatty acid compositions were compared along the mushroom species, it has been showed that linoleic and oleic acids percentages are dominant. The results obtained in this study are consistent with the previously reported results in the literature (Yilmaz et al. 2006; Goyal et al. 2015). In addition to linoleic acid, the other fatty acids such as oleic acid, palmitic acid, penthadecenoic acid and linoelaidic acids were also found in the mushroom samples (Table 2).

\section{Determination of malondialdehyde}

Lipid peroxidation was the process that involved the chain reactions of free radicals attacked to polyunsaturated fatty acid (PUFA). Result of the reaction leaded to lipid breakdown to yield products such as MDA. Therefore inhibition of lipid peroxidation has great importance in storage of PUFA rich foods like mushrooms.

Table 2 Fatty acid compositions of medicinal mushroom samples

\begin{tabular}{|c|c|c|c|c|c|}
\hline \multirow{2}{*}{ Fatyy acid } & \multicolumn{4}{|c|}{ Percentage of fatty acids (\%) } & \multirow{2}{*}{$p$ value } \\
\hline & L.volemus & M. elata & T. terrum & C. cibarius & \\
\hline Myristic acid (C14:0) & & & 0.37 & & 0.01 \\
\hline Penthadecanoic acid (C15:0) & 0.70 & $0.11^{\mathrm{c}}$ & $1.18^{\mathrm{c}}$ & $0.34^{\mathrm{c}}$ & 0.05 \\
\hline Cis-10-penthadecenoic Acid & 0.65 & $0.26^{\mathrm{c}}$ & $11.93^{\mathrm{b}}$ & $0.43^{\mathrm{c}}$ & 0.05 \\
\hline Palmitic acid (C16:0) & $18.76^{\mathrm{b}}$ & $12.73^{\mathrm{b}}$ & $14.33^{\mathrm{b}}$ & $20.69^{b}$ & 0.05 \\
\hline Oleic acid $(\mathrm{C} 18: 1 \mathrm{n} 9 \mathrm{c})$ & & $77.57^{\mathrm{a}}$ & ๑ & $15.04^{\mathrm{b}}$ & 0.01 \\
\hline Linoleic acid (C18:2n6c) & $78.93^{\mathrm{a}}$ & $7.24^{\mathrm{d}}$ & $66.25^{\mathrm{a}}$ & $50.54^{\mathrm{a}}$ & 0.01 \\
\hline Linoelaidic acid (C18:2n6t) & $0.16^{\mathrm{d}}$ & $1.36^{\mathrm{c}}$ & $4.63^{\mathrm{c}}$ & $12.39^{\mathrm{b}}$ & 0.01 \\
\hline Cis-11-eicosanoic acids. & 0.35 & & & & 0.01 \\
\hline$\Sigma$ SFA & $19.46^{\mathrm{b}}$ & $12.84^{\mathrm{b}}$ & $15.88^{\mathrm{b}}$ & $21.03^{\mathrm{b}}$ & 0.05 \\
\hline$\Sigma U S S F A$ & $80.08^{\mathrm{a}}$ & $86.19^{\mathrm{a}}$ & $82.81^{\mathrm{a}}$ & $78.4^{\mathrm{a}}$ & 0.05 \\
\hline$\Sigma$ MUFA & $1^{\mathrm{d}}$ & $77.83^{\mathrm{a}}$ & $11.93^{\mathrm{b}}$ & $15.47^{\mathrm{b}}$ & 0.01 \\
\hline$\Sigma P U F A$ & $79.09^{\mathrm{a}}$ & $8.36^{\mathrm{d}}$ & $70.88^{\mathrm{a}}$ & $62.93^{\mathrm{a}}$ & 0.05 \\
\hline$\Sigma U S S F A / S F A$ & $4.12^{\mathrm{c}}$ & $6.73^{d}$ & $5.21^{\mathrm{c}}$ & $3.73^{\mathrm{c}}$ & 0.05 \\
\hline
\end{tabular}

\footnotetext{
${ }^{\mathrm{a}, \mathrm{b}}$ Means within a rpw with no common supercript differ significantly (Duncan, $p<0.05$ )
} 


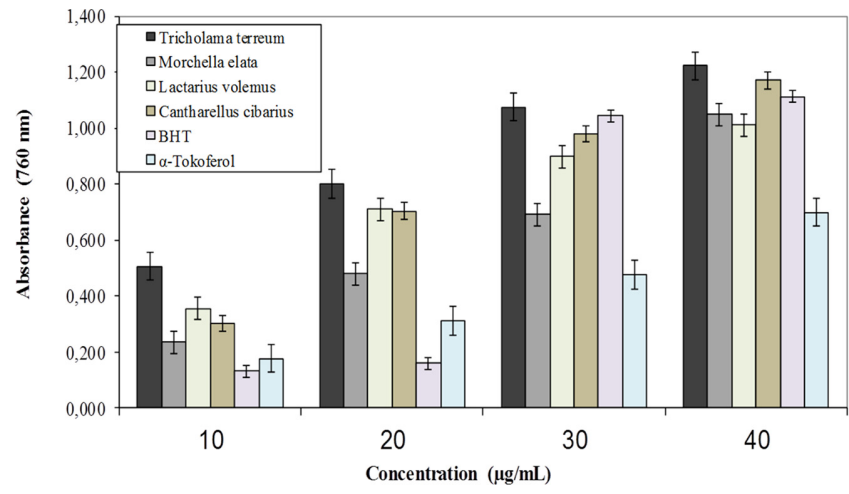

Fig. 2 Comparision of reducing power of different concentrations of Morchella elata, Lactarius volemus, Cantharellus cibarius, Tricholama terreum, BHT, and $\alpha$-tocopherol by spectrophotometric detection of the $\mathrm{Fe}^{+3}-\mathrm{Fe}^{+2}$ transformations at $700 \mathrm{~nm}$ (BHT: Butylated hydroxytoluene)

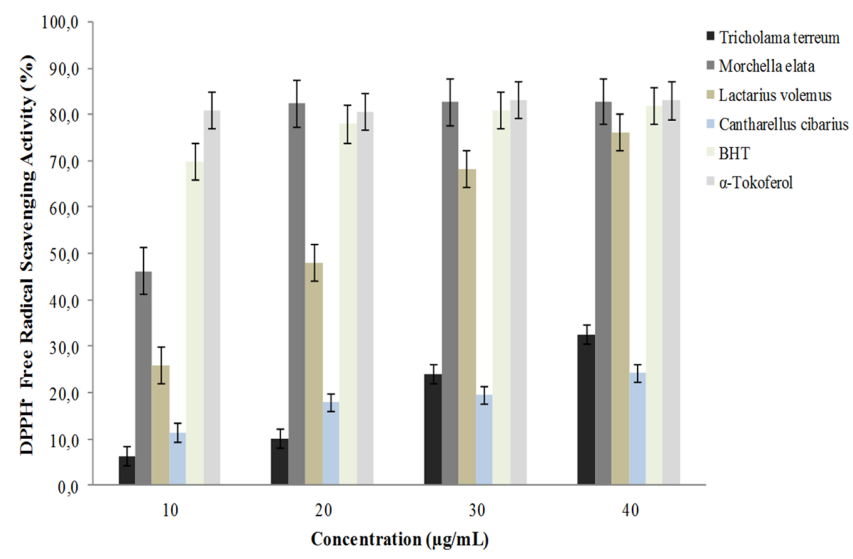

Fig. 3 Free radical scavenging activity of different concentrations of Morchella elata, Lactarius volemus, Cantharellus cibarius, Tricholoma terreum BHT, and $\alpha$-tocopherol by 1,1-diphenyl-2-picrylhydrazyl radicals (BHT: Butylated hydroxytoluene)

MDA analysis results were summarized in Fig. 1. It is clearly seen in the Fig. 1 that MDA contents were observed as $33.58 \mathrm{nmol} / \mathrm{g}$ DW in C. cibarus, $46.21 \mathrm{nmol} / \mathrm{g}$ DW in M. elata, $58.01 \mathrm{nmol} / \mathrm{g}$ DW in L. volemus, and $70.22 \mathrm{nmol} / \mathrm{g} \mathrm{DW}$ in T. terreum. MDA level could effectively reflect the content of free radicals produced by lipid peroxidation (Layali et al. 2015). In the present study, we observed that increase in the MDA content was associated with USFA/SFA ratio in C. cibarus, L. volemus, and T. terreum mushroom species. On the contrary, the ratio of USFA/SFA of M. elata was found high despite low MDA content (Fig. 1 and Table 2). This could be due to high fat-soluble vitamins content or high antioxidant capacity of $M$. elata. Obtained results in this study obviously showed that free radical scavenging activity of $M$. elata is higher than the other mushroom species (Fig. 2).

\section{Determination of reducing power}

Ferric reduction power of a compound or an extract can be used with one of the indicators of antioxidant capacity (Demirtas et al.

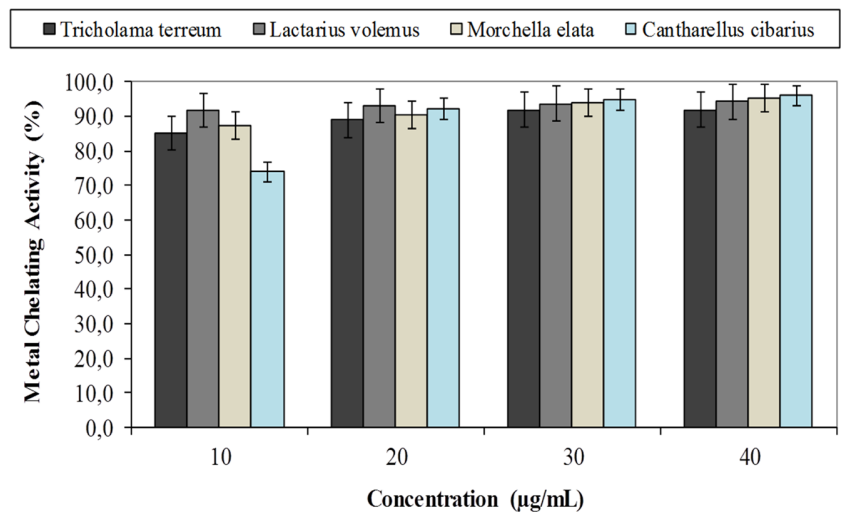

Fig. 4 Metal chelating effects of different concentrations of Morchella elata, Lactarius volemus, Cantharellus cibarius, Tricholoma terreum, BHT, and $\alpha$-tocopherol on ferrous ions

2013). Ferric reduction power of mushroom species in this study were shown in Fig. 2 and results were compared to BHT and $\alpha$ tocopherol. The mushroom species activities had higher than $\alpha$ tocopherol but lower than BHT. The differences were statistically significant $(p<0.05)$. Reducing power of methanol extract of all of mushroom species in this study have been found higher than alpha-tocopherol but lower than BHT. The activity of Tricholoma terreum has been found higher than the other mushroom species (Fig. 2).

\section{Free radical scavenging activity}

Scavenging of DPPH radicals was determined by the decrease of the absorbance at $517 \mathrm{~nm}$ as a result of the interactions between DPPH radicals and antioxidants. Fig. 3 illustrates a significant $(p<0.05)$ decrease in the concentration of DPPH radical due to the scavenging ability of mushroom species with respect to a positive control. Methanol extract of the mushroom species, except for $T$. terreum, showed strong DPPH scavenging activity at $10 \mu \mathrm{g} / \mathrm{mL}$ concentration. The scavenging activity of the samples and the standards on the DPPH radical followed the order of Morchella elata $>\alpha$-tocopherol $>$ BHT $>$ Lactarius volemus $>$ Cantharellus cibarius $>$ Tricholoma terreum with inhibition percentages of 82 , $80,77,48$ and 17 at $20 \mu \mathrm{g} / \mathrm{mL}$ concentrations, respectively. These results indicated that methanol extract of Morchelal elata has better effect on scavenging free radicals among the all four species.

\section{Chelating effect on ferrous ions}

As shown in Fig. 4, the formation of the $\mathrm{Fe}^{2+}$-ferrozine complex was prevented by the extracts of mushroom samples. The metal chelating capacity of $30 \mu \mathrm{g} / \mathrm{mL}$ concentration of Tricholama terreum, Lactarius volemus, Morchella elata, and Cantharellus cibarius were found as 92, 93, 94 and $95 \%$, respectively. The differences were accepted as statistically insignificant between the samples $(p>0.05)$. 
The data obtained from Fig. 4 reveals that the mushrooms used demonstrate marked capacity of iron binding which could be explained by their action as peroxidation protector related to probable iron binding capacity.

Acknowledgments The authors are grateful to Gaziosmanpasa University, and the TR State Planning Organization (DPT) for their support. This investigation made in Biochemistry and Plant Research Laboratory (BALAB) of Gaziosmanpasa University.

\section{References}

Brandwilliams W, Cuvelier ME, Berset C (1995) Use of a Free-Radical Method to Evaluate Antioxidant Activity. Food Sci Technol-Leb 28: 25 30

Canabady-Rochelle LLS, Harscoat-Schiavo C, Kessler V, Aymes A, Fournier F, Girardet JM (2015) Determination of reducing power and metal chelating ability of antioxidant peptides: Revisited methods. Food Chem 183: 129-135

Cantellops D, Reid AP, Eitenmiller RR, Long AR (1999) Determination of lipids in infant formula powder by direct extraction methylation of lipids and fatty acid methyl esters (FAME) analysis by gas chromatography. J Aoac Int 82: 1128-1139

Demirtas I, Erenler R, Elmastas M, Goktasoglu A (2013) Studies on the antioxidant potential of flavones of Allium vineale isolated from its water-soluble fraction. Food Chem 136: 34-40

Dinis TCP, Madeira VMC, Almeida LM (1994) Action of Phenolic Derivatives (Acetaminophen, Salicylate, and 5-Aminosalicylate) as Inhibitors of Membrane Lipid-Peroxidation and as Peroxyl Radical Scavengers. Arch Biochem Biophys 315: 161-169

Ebrahimzadeh MA, Nabavi SM, Nabavi SF, Eslami S (2010) Antioxidant and Free Radical Scavenging Activities of Culinary-Medicinal Mushrooms, Golden Chanterelle Cantharellus cibarius and Angel's Wings Pleurotus porrigens. Int J Med Mushrooms 12: 265-272

Elbatrawy EN, Ghonimy EA, Alassar MM, Wu FS (2015) Medicinal Mushroom Extracts Possess Differential Antioxidant Activity and Cytotoxicity to Cancer Cells. Int J Med Mushrooms 17: 471-479

Falandysz J, Drewnowska M (2015) Macro and trace elements in Common Chanterelle (Cantharellus cibarius) mushroom from the European background areas in Poland: Composition, accumulation, dietary exposure and data review for species. J Environ Sci Heal B 50: 374-387

Goyal R, Grewal RB, Goyal RK (2015) Fatty Acid Composition and Dietary Fibre Constituents of Mushrooms of North India. Emir J Food Agric 27:
927-930

Layali I, Tahmasbpour E, Joulaei M, Gholam S, Jorsaraei A, Farzanegi P (2015) Total Antioxidant Capacity and Lipid Peroxidation in Semen of Patient with Hyperviscosity. Cell J 16: 554-559

Manzi P, Aguzzi A, Pizzoferrato L (2001) Nutritional value of mushrooms widely consumed in Italy. Food Chem 73: 321-325

Money NP (2016) Are mushrooms medicinal? Fungal Biol-Uk 120: 449-453

Muka T, Stringa N, Brahimaj A, Zaciragic A, Kraja B, Dehghan A, Hofman A, Kiefte-De Jong JC, Franco OH (2015) Total antioxidant capacity of diet and plasma markers of oxidant-antioxidant status are associated with low-grade chronic inflammation: the rotterdam study. http://www. erasmusage.com/wp-content/uploads/2015/09/womens-health-ESC-2015Muka-total-anitoxidant-capacity.pdf. Accessed 3 Fabruary 2017

Muszynska B, Sulkowska-Ziaja K, Ekiert H (2013) Phenolic acids in selected edible basidiomycota species: Armillaria mellea, Boletus badius, Boletus edulis, Cantharellus cibarius, Lactarius deliciosus AND Pleurotus ostreatus. Acta Sci Pol-Hortoru 12: 107-116

Nitha B, Meera CR, Janardhanan KK (2007) Anti-inflammatory and antitumour activities of cultured mycelium of morel mushroom, Morchella esculenta. Curr Sci India 92: 235-239

Ohya T (1993) Reactivity of Alkanals Towards Malondialdehyde (Mda) and the Effect of Alkanals on Mda Determination with a Thiobarbituric Acid Test. Biol Pharm Bull 16: 1078-1082

Oyaizu M (1988) Antioxidative Activities of Browning Products of Glucosamine Fractionated by Organic-Solvent and Thin-Layer Chromatography. J Jpn Soc Food Sci 35: 771-775

Qin DW, Gu ZW, Guo JY (2015) Medicinal Mushroom for Prevention of Disease of Modern Civilization. Evid Based Complement Alternat Med 812725

Reis FS, Pereira E, Barros L, Sousa MJ, Martins A, Ferreira ICFR (2011) Biomolecule Profiles in Inedible Wild Mushrooms with Antioxidant Value. Molecules 16: 4328-4338

Sanmee R, Dell B, Lumyong P, Izumori K, Lumyong S (2003) Nutritive value of popular wild edible mushrooms from northern Thailand. Food Chem 82: 527-532

Vaz JA, Tavares C, Almeida GM, Martins A, Ferreira ICFR, Vasconcelos MH (2012) Mushroom Extract Increases P53 Expression and Causes Cell Cycle Arrest and Apoptosis in a Breast Cancer Cell Line. Ann Oncol 23: 28-29

Yilmaz N, Solmaz M, Turkekul I, Elmastas M (2006) Fatty acid composition in some wild edible mushrooms growing in the middle Black Sea region of Turkey. Food Chem 99: 168-174

Yin X, Feng T, Li ZH, Dong ZJ, Li Y, Liu JK (2013) Highly Oxygenated Meroterpenoids from Fruiting Bodies of the Mushroom Tricholoma terreum. J Nat Prod 76: 1365-1368 